\title{
EXTREME WATER LEVEL EXCEEDANCE PROBABILITIES AROUND AUSTRALIA
}

\author{
Leigh R. MacPherson ${ }^{1}$, Ivan D. Haigh ${ }^{1,2}$, Matthew S. Mason ${ }^{3}$, E.M.S. Wijeratne', \\ Charitha B. Pattiaratchi ${ }^{1}$, and Steve George ${ }^{4}$
}

\begin{abstract}
The potential impacts of extreme water level events on our coasts are increasing as populations grow and sea levels rise. To better prepare for the future, coastal engineers and managers need accurate estimates of average exceedance probabilities for extreme water levels. In this paper, we estimate present day probabilities of extreme water levels around the entire coastline of Australia. Tides and storm surges generated by extra-tropical storms were included by creating a 61-year (1949-2009) hindcast of water levels using a high resolution depth averaged hydrodynamic model driven with meteorological data from a global reanalysis. Tropical cyclone-induced surges were included through numerical modelling of a database of synthetic tropical cyclones equivalent to 10,000 years of cyclone activity around Australia. Predicted water level data was analysed using extreme value theory to construct return period curves for both the water level hindcast and synthetic tropical cyclone modelling. These return period curves were then combined by taking the highest water level at each return period.
\end{abstract}

Keywords: water levels; storm surges; tropical cyclones; numerical modelling; average exceedance probabilities

\section{INTRODUCTION}

The impacts of extreme water level events occurring along low lying, highly populated and/or developed stretches of coastline can be devastating, including considerable loss of life and millions of dollars of damage to coastal infrastructure (Lowe et al. 2010). Recent major storm events (i.e. those arising from tropical cyclones Katrina, Sidr, Nargis, Irene and Yasi), have emphasized the destructive nature of coastal flooding arising from extreme water levels (Menéndez and Woodworth 2010). There is also a growing concern about the potential impacts of rising sea levels. Sea levels have risen by approximately $25 \mathrm{~cm}$ over the past 150 years (Bindoff et al. 2007), and the rate of rise is expected to accelerate throughout the $21^{\text {st }}$ century (Meehl et al. 2007). As sea levels rise, smaller storm surge events will be required to reach given water levels, increasing the frequency of extreme water levels (Haigh et al. 2011a). Therefore, it is vital that average exceedance probabilities (AEP) of extreme water levels are evaluated so that coastal engineers and managers can make informed decisions and prepare for the future. The overall aim of this study was to determine AEP along the entire length of the Australian coastline.

Traditionally, exceedance probabilities for extreme water levels have been calculated from tidegauge measurements. Unfortunately, there are two main problems with applying this approach in the Australian region. First, there are relatively few tide gauge sites located around the coastline with records long enough ( $>30$ years) to accurately estimate exceedance probabilities using conventional extreme analysis methods (Haigh et al. 2010). As the characteristics of extreme water levels vary considerably around the coast of Australia, a simple interpolation of probabilities between the widely spaced tide gauge sites does not provide an accurate spatial representation of extreme levels. Second, the probabilities of extreme water levels caused by intense tropical cyclones cannot be estimated solely using tide gauge records. Even in records covering many decades to a century, there are typically only a few observations of large tropical cyclone-induced water levels because the low spatial density of tides gauges means it is relatively rare that a tropical cyclone will pass close enough to a gauge site to generate extreme levels (Harper 2001). Hence, using the observational record only to make extrapolation to low probabilities of occurrence is inadequate (McInnes et al. 2009).

This study involved three main stages of work. In the first stage, which was undertaken to address the first issue (i.e. poor spatial coverage of long observational data sets), a 61-year hindcast of water levels was created for the Australian continental shelf region. In the second stage, undertaken to address the second issue (i.e. estimating probabilities of extreme water level arising from tropical cyclones), a database of many thousands of years of synthetic tropical cyclones was generated and the storm surge response was modelled. The third stage involved combining the results of the first to stages.

${ }^{1}$ The School of Environmental Systems Engineering and the UWA Oceans Institute, The University of Western Australia, M470, 35 Stirling Highway, WA, Crawley 6009, Australia.

2 Ocean and Earth Science, National Oceanography Centre, University of Southampton, Waterfront Campus, European Way, Southampton, SO16 3HZ, UK.

${ }^{3}$ Risk Frontiers, Natural Hazards Research Centre, Macquarie University, NSW 2109, Australia.

${ }^{4}$ Antarctic Climate and Ecosystems Cooperative Research Centre, Private Bag 80, Hobart, Tasmania 7001, Australia. 


\section{STAGE 1}

\section{Model Configuration}

A depth averaged hydrodynamic model was configured for the entire Australian coastline using the Danish Hydraulic Institute's Mike21 FM (flexible mesh) model (DHI, 2010). The model mesh (Figure 1) has a resolution of between $20-80 \mathrm{~km}$ at the open tidal boundaries, reducing to $\sim 10 \mathrm{~km}$ along the coastline. The mesh is refined over the continental shelves to more accurately predict tides, and extends north of Australia to include seasonal and inter-annual mean sea level variations caused by monsoonal winds.

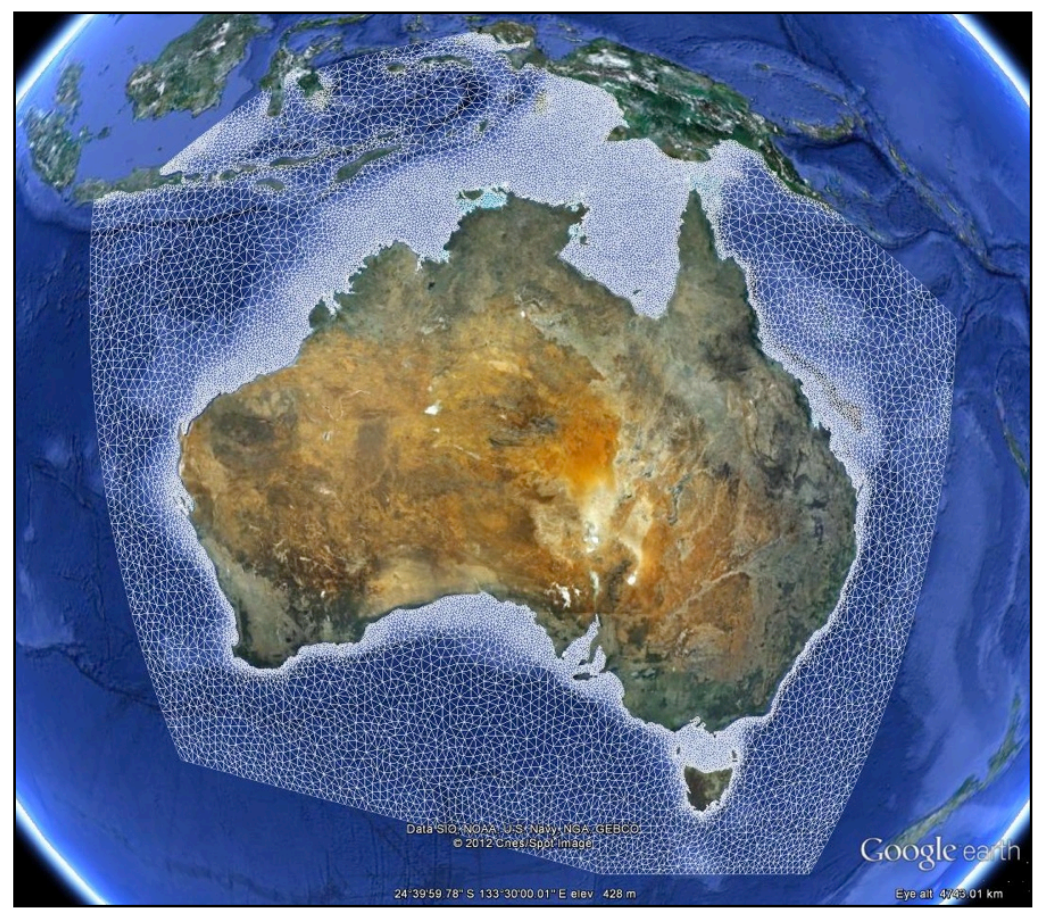

\section{Figure 1. Model mesh}

In order to generate the tidal component of water levels, the open model boundaries were driven with tidal levels derived from TPXO7.2 global ocean model (Egbert et al. 1994; Egbert and Erofeeva 2002). To generate the storm surge component of water levels, the model was forced with atmospheric pressure fields and $\mathrm{u}$ and $\mathrm{v}$ components of $10 \mathrm{~m}$ wind fields, obtained from the US National Center for Environmental Prediction's/National Center for Atmospheric Research's (NCEP/NCAR) global reanalysis (Kalnay et al. 1996; Kistler et al. 2001). The model was run for the 61-year period from 1949 to 2009 . Results were output for each model grid cell every hour. As the model was run with both tides and meteorological forcing, non-linear interactions between tide and surge components were included (Horsburgh and Wilson 2007).

\section{Model Validation}

The model was validated against measurements from 30 tide-gauges (Figure 2), which, with the exception of Milner Bay, all have records of at least 30 years. The tide-gauge records were obtained from the Australian National Tidal Centre. The records were rigorously checked for common errors such as data spikes and spurious values, which have been excluded.

Sixty-one year time-series of predicted water levels were extracted from the hydrodynamic model at the grid points closest to the corresponding tide gauges. The de-trended water level measurements and predicted model time-series at each site were then separated into tide and surge components (Pugh 1987). The tidal component was estimated using the Matlab T-Tide harmonic analysis software (Pawlowicz et al. 2002) and the surge component was calculated by subtracting the tidal component from the total water level time-series. The two components were validated separately, before a comparison of the measured and predicted total water levels was undertaken. 

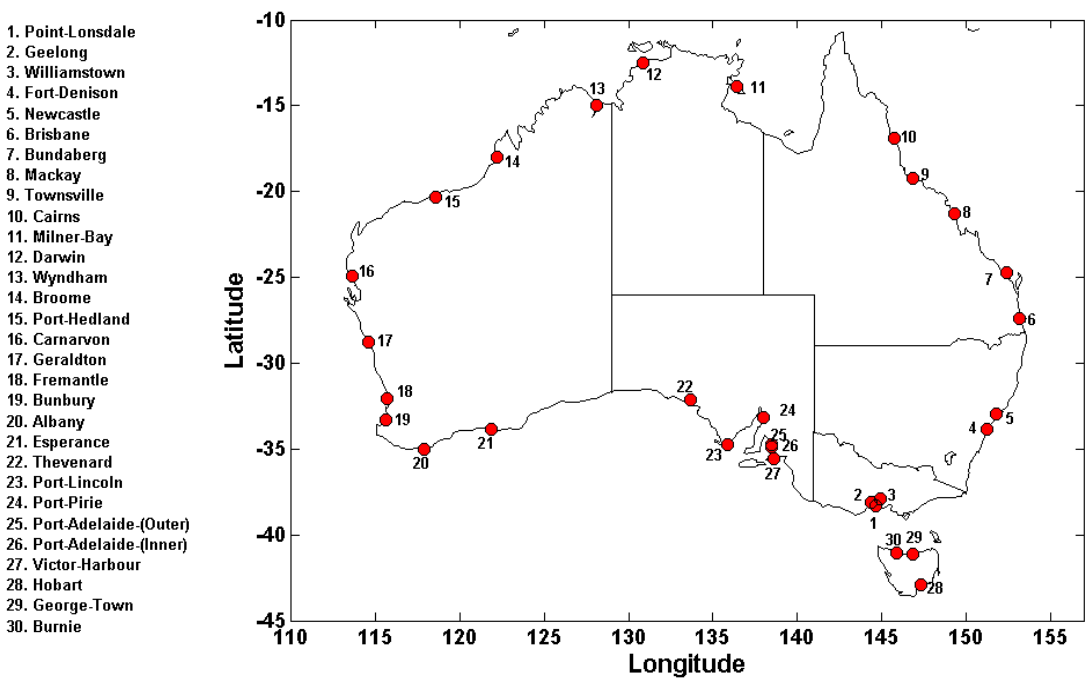

Figure 2. Location of tide gauge sites around the coastline of Australia with high frequency (at least hourly) water level records longer than $\mathbf{3 0}$ years. Note: Milner Bay does not have $\mathbf{3 0}$ years of data, however, it has been included so that there is a validation site in the Gulf of Carpentaria.

Comparison of the measured and predicted amplitudes of the four main tidal constituents can be seen in Figure 3. The good agreement across all validation sites demonstrates that the model accurately reproduces the observed characteristics of tides around Australia. Comparison of the measured and predicted storm surge component at five tide-gauge locations along the southern coastline of Australia can be seen in Figure 4, for the year 1995. The model accurately captures the characteristics of surges throughout the year in this region, which is dominated by extra-tropical cyclones, but underestimates storm surges in northern tropical regions.
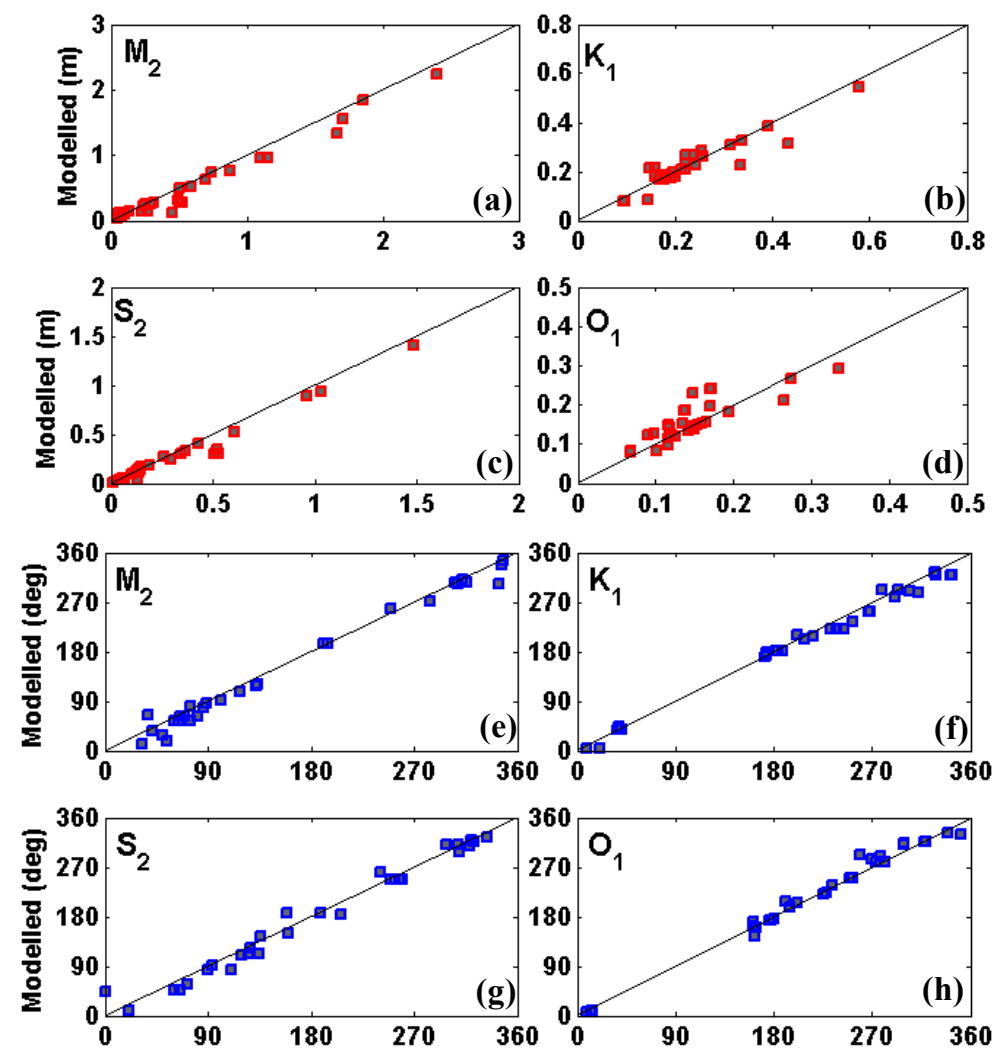

Figure 3. Comparison of the measured and predicted amplitudes $(a, b, c, d)$ and phases $(e, f, g, h)$ of the four main tidal constituents for the $\mathbf{3 0}$ validation sites for 1995 . 

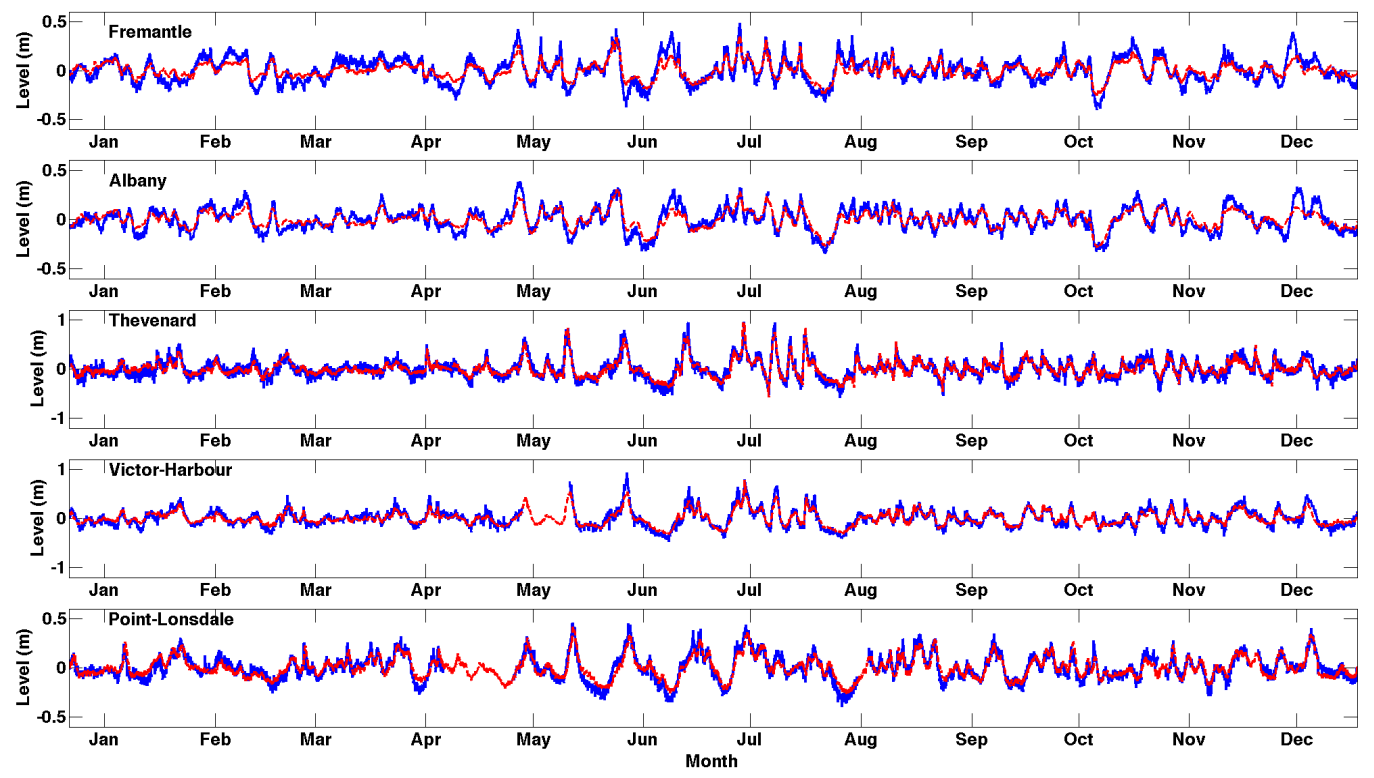

Figure 4. Comparison of the measured (blue) and predicted (red) surge component for 1995 at select sites around southern Australia.

\section{Return levels and periods}

For each model grid-point, a time-series of annual maximum predicted waters levels were extracted and then used to estimate AEP. This was done using the annual maximum method fitted to the Generalized Extreme Value (GEV) distribution (Coles, 2001). The extremal analyses were undertaken using the ismev package implemented in the statistical language $\mathrm{R}$.

Comparison of the AEP estimated from the predicted hindcast and measured tide gauge data can be seen in Figure 5, for the 30 validation sites. The agreement between predicted and measured AEP is reasonable at most sites. However, the predicted curves typically under estimate the return levels at higher return periods for sites around western, northern and north-eastern Australia that are strongly influenced by tropical cyclones (i.e. Carnarvon around to Mackay). This is because the meteorological fields used to force the hydrodynamic model only weakly include the effects of tropical cyclones. Also, multi-decadal periods yield insufficient instances of tropical cyclones to enable the use of traditional extreme value extrapolation techniques. Therefore, a second stage of this study was conducted to include tropical cyclone induced surges in AEP estimation.
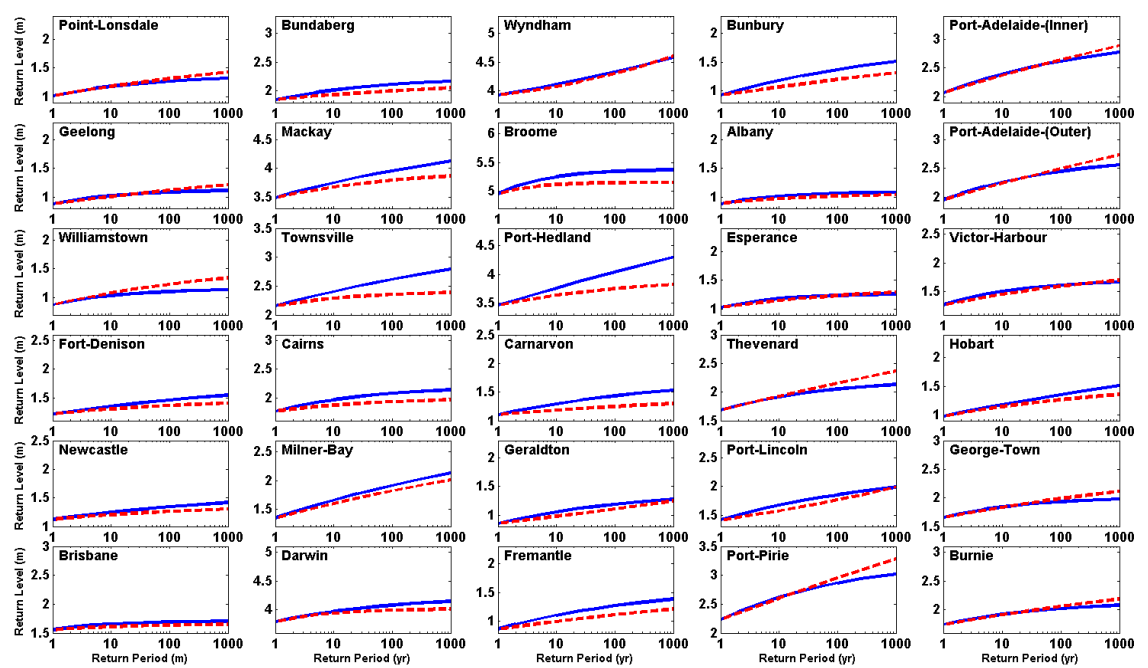

Figure 5. Comparison of the predicted (red) and measured (blue) return period curves for 2010 (relative to Australian Height Datum) at the $\mathbf{3 0}$ validation sites. 


\section{STAGE 2}

The aim of the second stage of the study was to more accurately include tropical cyclone-induced surges in the estimation of total water level probabilities. This was done by creating a database of synthetic tropical cyclones, representing 10,000 years of cyclone activity around Australia, and using hydrodynamic numerical modelling to simulate the water levels produced by these events.

\section{Synthetic Tropical Cyclone Database}

A 10,000-year synthetic tropical cyclone database was developed using observations held by the Bureau of Meteorology (BOM). Data limitations and inconsistencies exist for the period before the implementation of satellite tracking (Holland 1980; Harper et al. 2008), hence only the post-satellite era data (i.e. 1969/70 tropical cyclone season onwards) to 2008/09 was used to developed baseline climatological statistics. The tropical cyclone wind model generated and tracked synthetic activity within approximately $600 \mathrm{~km}$ of the Australian coastline from Coffs Harbour (New South Wales) on the east coast to Augusta (Western Australia) on the west. Genesis of tropical cyclones occurred within this region or along one of a series of gates that lined the outer model boundary. Poisson sampling was used to generate an appropriate number of events based on annual event frequencies for each gate or nine domain sub-regions. Monte-Carlo sampling of probability distributions was then used to determine the event's initial characteristics (ambient pressure, central pressure, forward speed, direction and radius). To facilitate the application of an auto-regressive approach to simulation of storm tracking (Vickery et al. 2000), model constants were determined using multivariate regression analysis of storm behaviour within domain sub-regions of similar storm behaviour using the historic record. Cyclone paths were generated as a series of straight lines with a temporal resolution of six hours (interpolated linearly to one hour). Wind and atmospheric pressure fields were then determined using a double vortex model (Cardone et al. 1994). This model avoids a rapid decay seen with the standard Holland model (Holland, 1980) and gives better agreement with observed data at large radii (McConchie et al 1999).
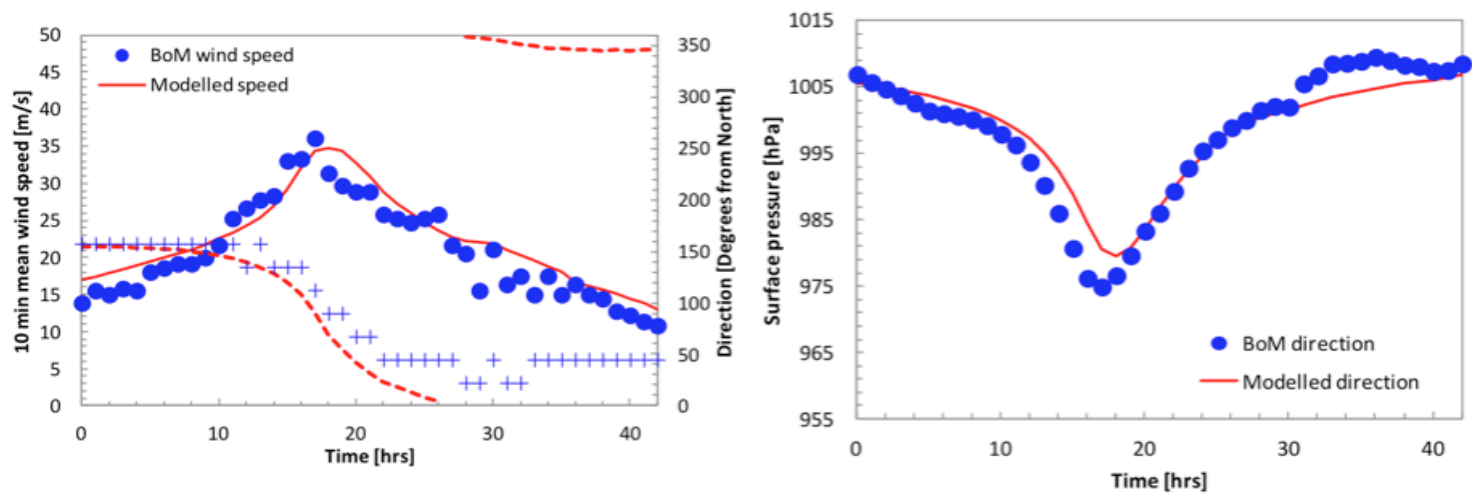

Figure 6. Predicted (blue) and measured (red) wind speed, direction and atmospheric pressure time-series for Flinders Reef meteorological stations during the passage of tropical cyclone Yasi in Feb 2011.

Model output was validated against observations from 27 automatic weather stations at a number of locations around the Australian coastline and at reef/island sites, all with meteorological records longer than 30 years. A comparison of the predicted and measured wind speed, direction and atmospheric pressure at the Flinders Reef meteorological station is shown in Figure 6 for tropical cyclone Yasi. The historic tropical cyclone tracks from the BOM database between the 1969/70 and 2008/09 season are shown in Figure 7, along with the synthetic tracks from the model for a 1,000-year period.

A validation exercise was then undertaken to determine the accuracy of tropical cyclone-induced storm surge events that could be simulated using the hydrodynamic model. Comparisons between the predicted and measured storm surge at the Broome and Townsville tide-gauges for tropical cyclones Rosita and Althea respectively can be seen in Figure 8. The model predicts the maximum surge at Broome for cyclone Rosita to within $1 \mathrm{~cm}$ and at Townsville for cyclone Althea to within $5 \mathrm{~cm}$. 
(a) Observed 1970-2008

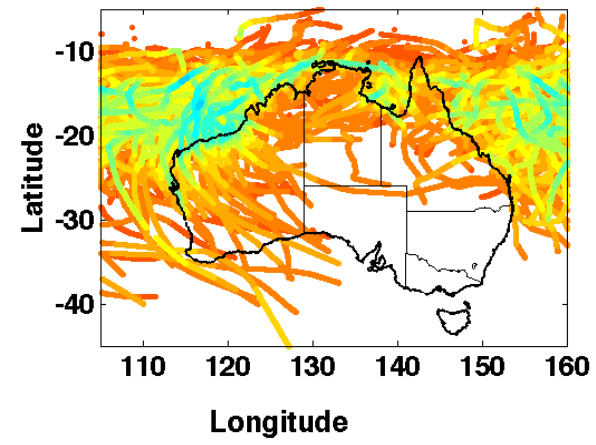

(b) Synthetic 1000 yrs

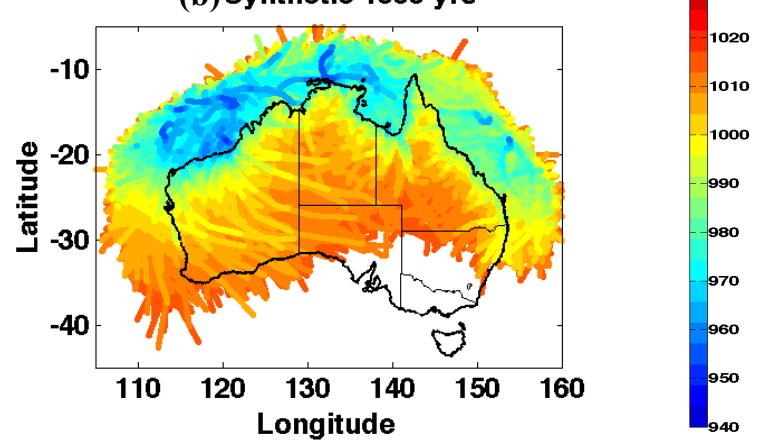

Figure 7. (a) Observed tropical cyclone tracks for the 39 year period between 1970 and 2008; and (b) Synthetic tropical cyclone tracks for a 1,000 year period.

\section{Tide Surge Interactions}

To decrease overall run times, simulations of tropical cyclone-induced surges could be run without the inclusion of tides. However, due to the possible affects of non-linear interactions between tide and surge (Horsburgh and Wilson 2007), surge predictions done in this way may be inaccurate. Therefore, to determine if non-linear effects between tide and surge exist around Australia, two sets of simulations were undertaken, for tropical cyclones Althea and Rosita. For both cyclones, an initial run was undertaken in which the model was driven only with meteorological forcing. Four additional runs were undertaken for both events in which the model was driven with both tidal forcing and meteorological forcing. The timing of meteorological forcing was artificially adjusted for each simulation so the peak surge occurred around the time of low water, on the rising tide, high water and on the ebb tide.

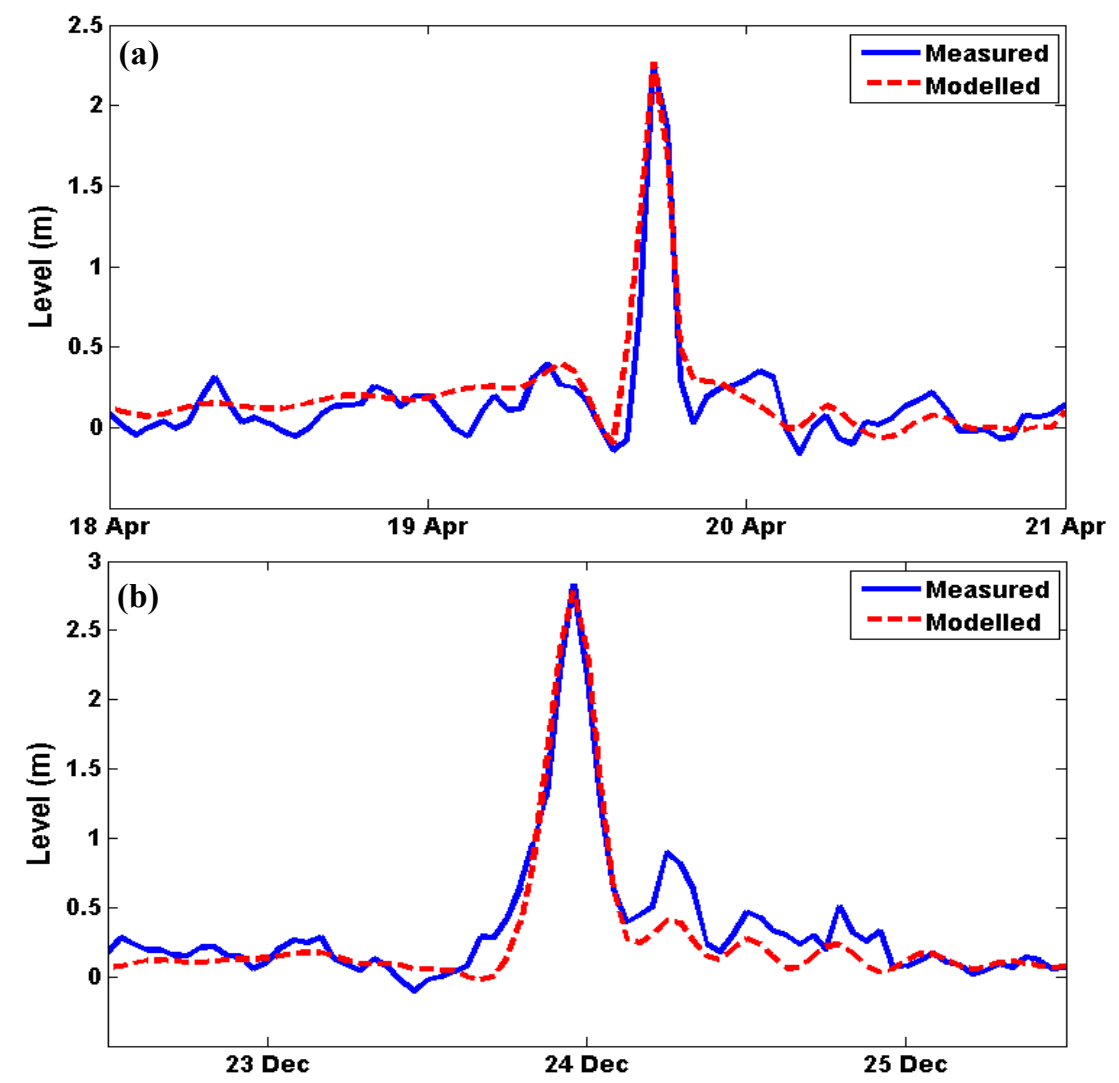

Figure 8. (a) Comparisons between the measured (blue) and predicted (red) surge time-series at (a) Broome for cyclone Rosita, and (b) Townsville for cyclone Althea. 
For each simulation that involved tidal and meteorological forcing, a comparison of the surge levels was conducted by removing the tidal levels predicted by the tide-only simulations. The difference between surge heights measured on the east coast were minor, making up about $10 \%$ of the total surge height. However, on the west coast, where the tidal range is much larger (about $10 \mathrm{~m}$ compared to about $1 \mathrm{~m}$ ), the difference in height was around $1 \mathrm{~m}$, equivalent to around $1 / 3$ of the total surge height (see Figure 9). For both locations, the smallest surge occurred on the tidal flood, and the highest on the tidal ebb. Therefore, to ensure that tide-surge interactions are included throughout the model domain, tropical cyclone simulations included both tide and surge components.
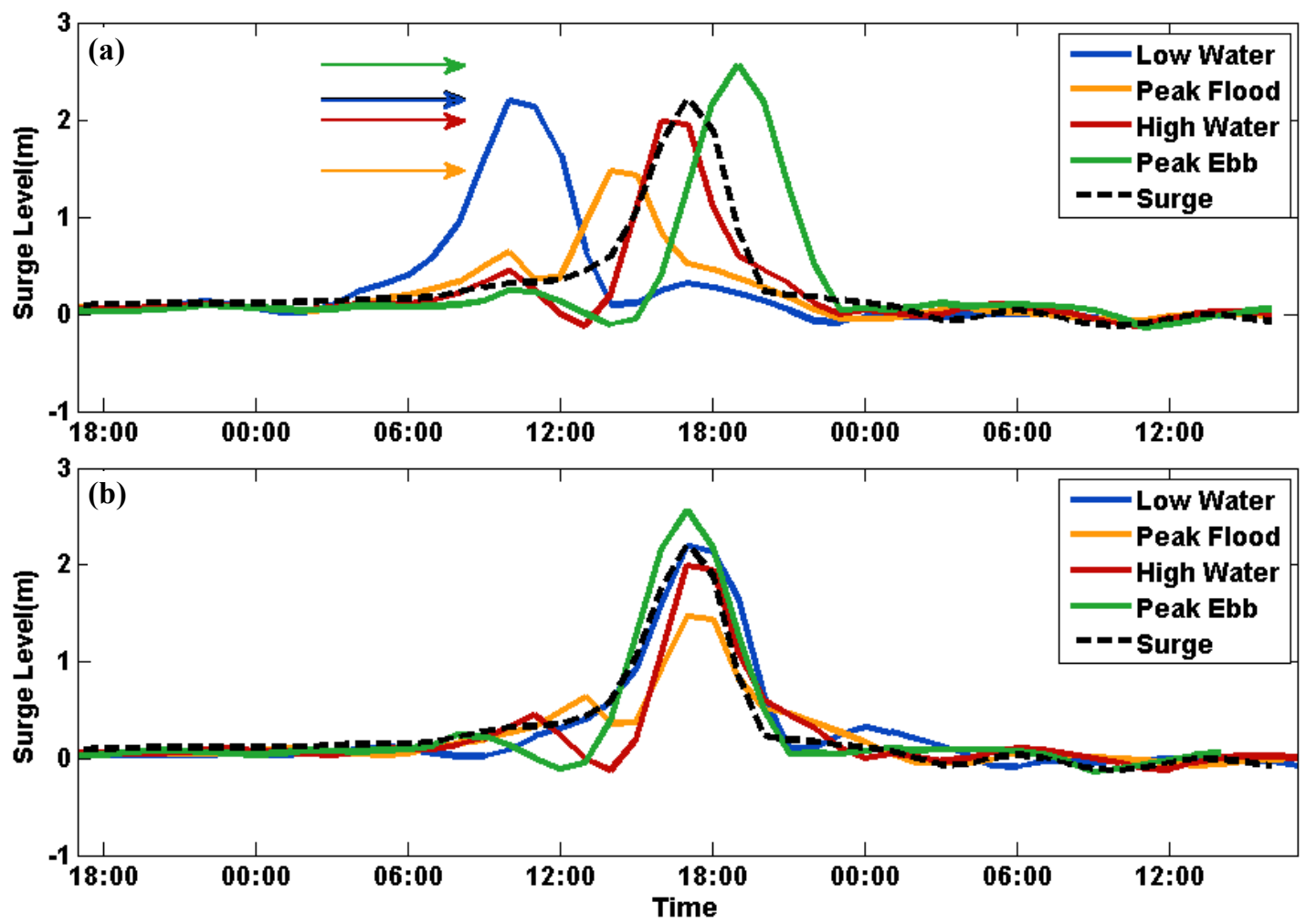

Figure 9. Tide-surge interaction at Broome associated with tropical cyclone Rosita. (a) surge levels for the four different tidal states and surge only simulation; (b) surge levels for the four different tidal states and surge only simulation, but re-adjusted for the time offset.

\section{Simulations}

For each synthetic tropical cyclone event that was generated by the stochastic model (about 75,000 in total), the hydrodynamic model was run with tides included to account for tide-surge interactions. Tides were selected by taking a random year from a 19-year period (to include the 18.6 year lunar nodal cycle; Haigh et al., 2011b) and a random hour in this year. The selection of the hour was weighted to account for the tropical cyclone season. Each simulation started with water elevation and $u$ and v velocities pre-set to avoid the costly warm-up needed when modelling tides.

\section{Return Levels}

For each year of the 10,000-year period, the maximum water levels were calculated for each of the coastal grid points. Annual maxima $(x)$ were then ranked in order of size (i.e. $\mathrm{x}_{1}<\mathrm{x}_{2}<\ldots<\mathrm{x}_{\mathrm{n}}$ ) and the extreme distribution $(\mathrm{F}[\mathrm{x}])$ was estimated by dividing the rank by the total number of years $(\mathrm{n})$, as follows (Coles, 2001):

$$
F[x]=\frac{i}{n} \quad \text { for } \mathrm{x}_{\mathrm{i}}<\mathrm{x}<\mathrm{x}_{\mathrm{i}+1}
$$

Using this method, for the second highest predicted water level at a given location over the 10,000 year simulation period, an exceedance probability of 0.0002 is obtained, corresponding to a return period of 5,000 years. A normal kernel density estimate was used to smooth the distribution and give return 
levels at any given return period. The 1,000-year surge level, estimated in this way, is shown in Figure $10 \mathrm{~b}$, for the entire coastline. For comparison, the corresponding estimates derived in stage 1 using the 61-year hindcast and the annual maximum method, are shown in Figure 10a.
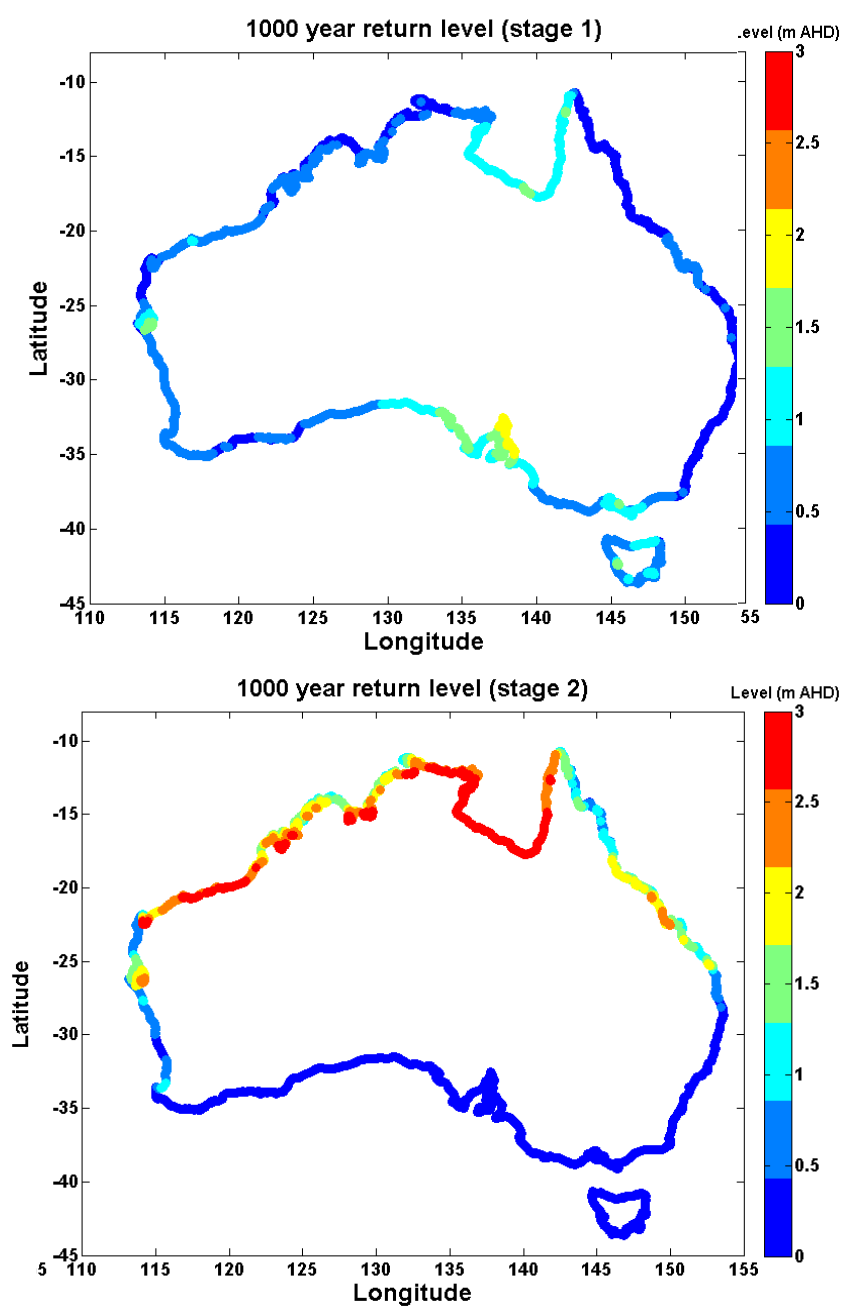

Figure 10. 1,000-year surge return levels for 2010 (relative to AHD) at the model coastal grid points estimated in (a) stage 1 and (b) stage 2 (tropical cyclones).

The predicted total water level return period curves calculated in stages 1 and 2 are shown in Figure 11 for the grid cells nearest to the 30 validation sites. It is interesting to consider at what return periods the tropical cyclone-induced total water levels exceed the return levels estimated from the 61year hindcast. From Albany to Newcastle, the extreme total water levels are completely dominated by extra-tropical storm events, hence the stage 1 estimates are much higher. However, for the northern sites the upper return periods are dominated by tropical cyclones and hence the estimates from stage 2 are higher.

\section{STAGE 3}

To create a dataset for coastal engineers, managers and researchers, the estimates from stages 1 and 2 were combined simply by taking the higher level at each return period. These values were then linearly interpolated to $1 / 60^{\text {th }}$ of a degree $(\sim 2 \mathrm{~km})$ intervals around the coast, to provide higher resolution coverage, and are freely available via a web-based tool (www.sealevelrise.info). The combined 1,000-year water levels are shown in Figure 12 for the entire Australian coastline. 


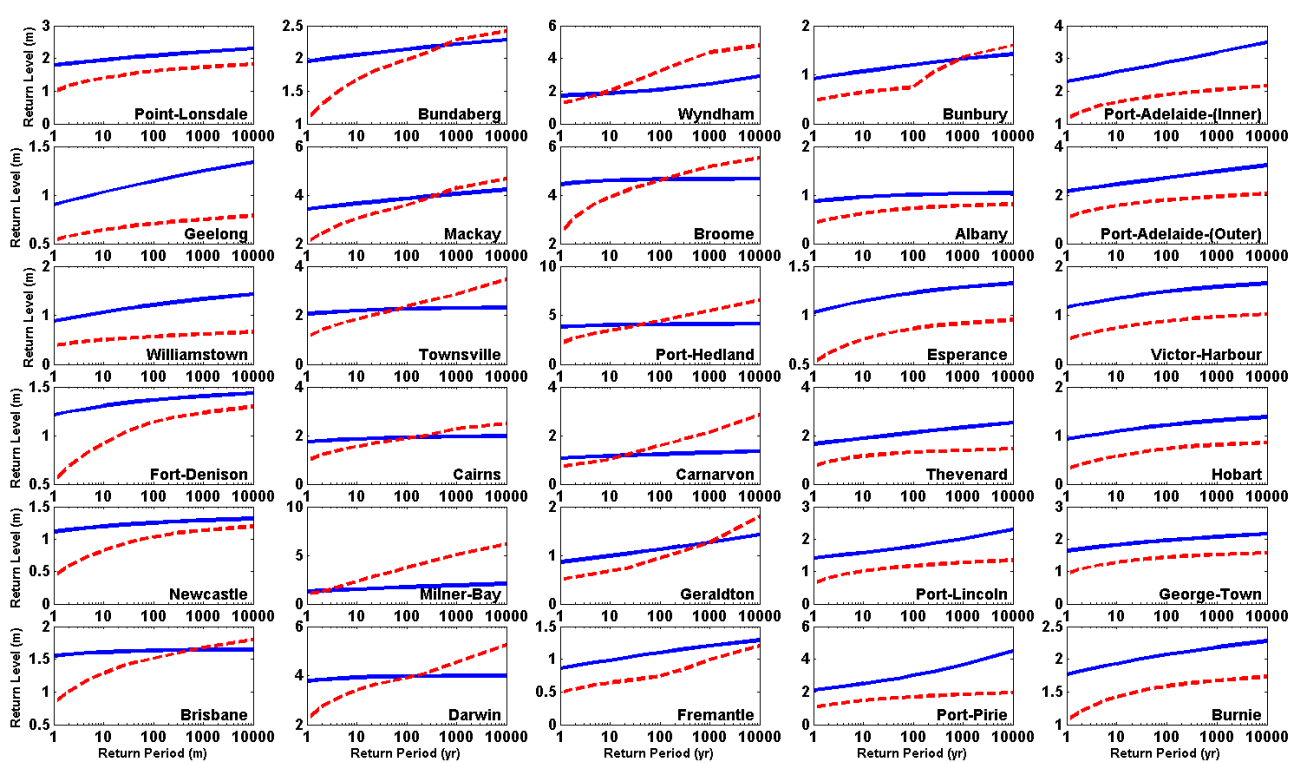

Figure 11. Comparison of the return period curves for 2010 (relative to Australian Height Datum) estimated in stage 1 (blue) and stage 2 (red) at the 30 validation sites.

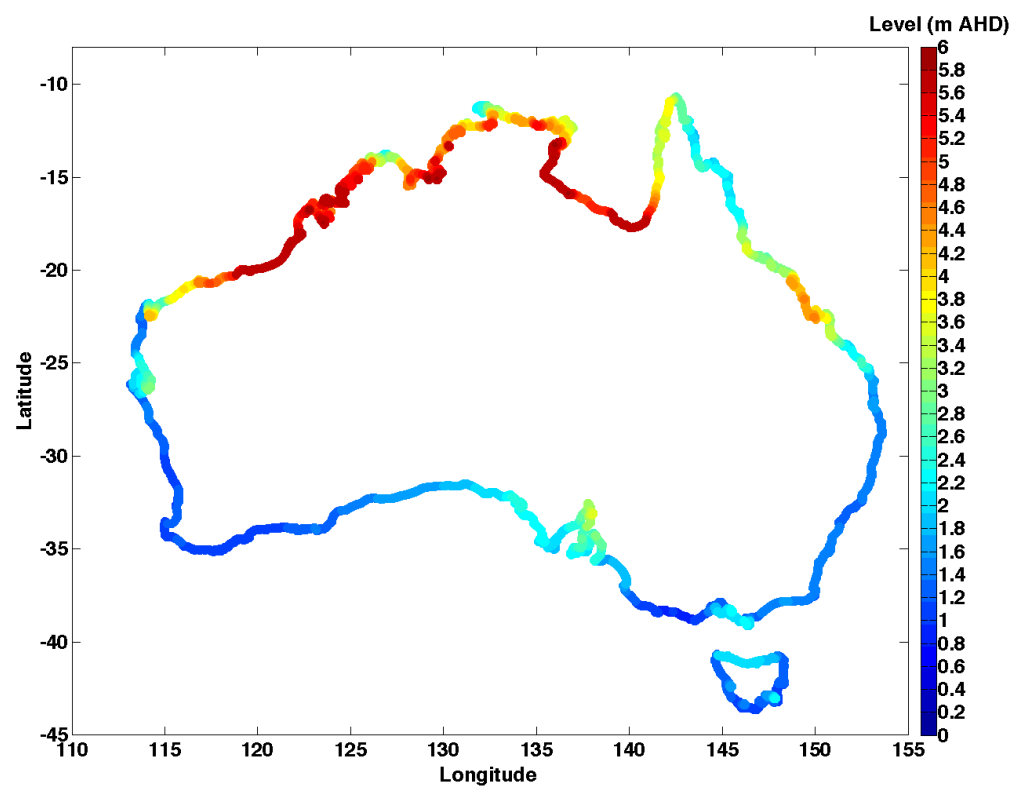

Figure 12. Comparison of the total water level return period curves for 2010 (relative to Australian Height Datum) estimated in stage 1 (blue) and stage 2 (red) at the 30 validation sites.

\section{CONCLUSIONS}

This is the first study to provide estimates of total water level AEP for the entire coastline of Australia, arising from a combination of tide and surges generated by both extra-tropical and tropical cyclones. A high-resolution depth averaged hydrodynamic model was configured for the Australian continental shelf region and used to generate a 61-year time-series of historic water levels. This predicted dataset was validated against measurements from tide gauge sites and then used to estimate AEP around the entire Australian coastline. A statistical model of the tracks and central pressures of tropical cyclones was developed to more accurately include tropical cyclone-induced surges in the estimation of extreme total water level probabilities, which were underestimated in the multi-decadal hindcast. This was then used to generate 10,000 years of synthetic tropical cyclone events in the Australian region, based on characteristics of tropical cyclone activity over the last 40 years. Wind and pressure fields were derived for these synthetic events and were used to drive the hydrodynamic model. 
Annual maximum levels for these synthetic events were calculated and used to estimate AEP around the coast. Theses estimate were combined with those derived from the multi-decadal hindcast to give a single estimate of present day extreme water level probabilities around the whole coastline of Australia. The described methodology could be applied to other regions of the world that are subject to both extra-tropical and tropical cyclones.

\section{ACKNOWLEDGEMENTS}

We would like to thank the Australian National Tidal Centre, Western Australian Department of Transport, Sydney Ports Corporation and Fremantle Ports for supplying the observational tide-gauge datasets. This study was funded by the Australian Department of Climate Change and Energy Efficiency and the Western Australian Department of Transport, and builds on an earlier study funded by the Western Australian Marine Science Institution. A technical report describing this study in more detail is available from: http://canute2.sealevelrise.info/Publications.

\section{REFERENCES}

Bindoff, N.L., Willebrand, J., Artale, V., Cazenave, A., Gregory, J., Gulev, S., Hanawa, K., Le Quéré, C., Levitus, S., Nojiri, Y., Shum, C.K., Talley L.D., Unnikrishnan, A., 2007. Observations: Oceanic climate change and sea level. In: Climate Change 2007: The physical science basis. Contribution of working group I to the Fourth Assessment Report of the Intergovernmental Panel on Climate Change. Editors: Solomon, S., Qin, D., Manning, M., Chen, Z., Marquis, M., Averyt, K.B., Tignor M., Miller H.L. Cambridge University Press, Cambridge, United Kingdom and New York, NY, USA, pp. 385-432.

Cardone, V.J., Cox, A.T., Greenwood, J.A, Thompson, E.F., 1994. Upgrade of tropical cyclone surface wind field model. Miscellaneous Paper, CERC-94-14, prepared for U.S. Army Corps of Engineers (101pp.).

Coles, S., 2001. An Introduction to Statistical Modelling of Extreme Values. Springer. (207pp.).

Egbert, G.D., Bennett, A.F., Foreman, M.G.G., 1994. TOPEX/POSEIDON tides estimated using a global inverse model. J. Geophys. Res., 99(C12), 24821-24852.

Egbert, G.D., Erofeeva, S.Y., 2002. Efficient Inverse Modeling of Barotropic Ocean Tides. Journal of Atmospheric and Oceanic Technology, 19(2), 183-204.

Haigh, I.D., Nicholls, R.J., Wells, N.C., 2010. A comparison of the main methods for estimating probabilities of extreme still water levels. Coastal Engineering, 57(9), 838-849.

Haigh, I.D., Nicholls, R.J., Wells, N.C., 2011a. Rising sea levels in the English Channel 1900 to 2100. Proceedings of ICE Maritime Engineering, 164 (2), 81-92.

Haigh, I.D., Eliot, M., Pattiaratchi, C., 2011b. Global influences of the 18.61 year nodal cycle and 8.85 year cycle of lunar perigee on high tidal levels, J. Geophys. Res., 116, C06025, doi:10.1029/2010JC006645.

Harper, B.A. (ed), 2001. Queensland climate change and community vulnerability to tropical cyclones - ocean hazards assessment stage 1-review of technical requirements. Report prepared by Systems Engineering Australia Pty Ltd in association with James Cook University Marine Modelling Unit, Queensland Government, 375 pp, March 2001.

Harper, B.A., Stroud, S.A., McCormack, M., West, S., 2008. A review of historical tropical cyclone intensity in northwestern Australia and implications for climate change trend analysis. Australian Meteorological Magazine, 57, 121-141.

Holland, G. J., 1980: An Analytic Model of the Wind and Pressure Profiles in Hurricanes. Monthly Weather Review, 108, 1212-1218.

Horsburgh, K.L., Wilson, C., 2007. Tide-surge interaction and its role in the distribution of surge residuals in the North Sea. Journal of Geophysical Research, 112, CO8003.

Kalnay, E., Kanamitsu, M., Kistler, R., Collins, W. Deaven, D., Gandin, L. Iredell, M., Saha, S., White, G., Woollen, J., Zhu, Y., Leetmaa, A., Reynolds, R., Chelliah, M., Ebisuzaki, W., Higgins, W., Janowiak, J., Mo, K.C. Ropelewski, C., Wang, J. Jenne, R., Joseph, D., 1996. The NCEP/NCAR 40-year reanalysis project Bull. Amer. Meteor. Soc. 77 437-70.

Kistler, R. Kalnay, E., Collins, W., Saha, S., White, G. Woollen, J. Chelliah, M. Ebisuzaki, W., Kanamitsu, M. Kousky, V., Dool, H., Jenne, R. and Fiorino, M., 2001. The NCEP-NCAR 50-Year Reanalysis: Monthly Means $\mathrm{CD}$ ROM and Documentation. Bulletin of the American Meteorological Society, 82(2), 247-267. 
Lowe, J.A., Woodworth, P.L., Knutson, T., McDonald, R.E., McInnes, K., Woth, K., Von Storch, H., Wolf, J., Swail, V., Bernier, N., Gulev, S., Horsburgh, K., Unnikrishnan, A.S., Hunter, J., Weisse, R., 2010. Past and future changes in extreme water levels and waves. In: Understanding sea-level rise and variability. (Church, J.A., Woodworth, P.L., Aarup T., Wilson, S. (eds)). WileyBlackwell.

McConochie, J.D., Mason, L.B., Hardy, T.A., 1999. A Coral Sea cyclone wind model intended for wave modelling. In: Proceedings of $14^{\text {th }}$ Conference on Coastal and Ocean Engineering, IEAust, Perth, 413-418.

McInnes K.L., Macadam I., Hubbert, G.D., O'Grady, J. D., 2009. A modelling approach for estimating the frequency of sea level extremes and the impact of climate change in southeast Australia. Natural Hazards, 51, 115-37.

Meehl, G.A., Stocker, T.F., Collins, W.D., Friedlingstein, P., Gaye, A.T., Gregory, J.M., Kitoh, A., Knutti, R., Murphy, J.M., Noda, A., Raper, S.C.B., Watterson, I.G., Weaver A.J., Zhao, Z.C., 2007. Global climate projections. In: Climate change 2007: The physical science basis. Contribution of working group I to the Fourth Assessment Report of the Intergovernmental Panel on Climate Change. Editors: Solomon, S., Qin, D., Manning, M., Chen, Z., Marquis, M., Averyt, K.B., Tignor M., Miller H.L., Cambridge University Press, Cambridge, United Kingdom and New York, NY, USA, pp. 747-845.

Menéndez, M., Woodworth, P.L., 2010, Changes in extreme high water levels based on a quasi-global tide-gauge dataset. J. Geophys. Res., 115 (C10), C10011.

Pawlowicz, R., Beardsley, B., Lentz, S., 2002. Classical tidal harmonic analysis including error estimates in MATLAB using T_TIDE. Computers \& Geosciences, 28(8), 929-937.

Pugh, D.T., 1987. Tides, surges and mean sea-level. A handbook for engineers and scientists. Wiley, Chichester, 472pp.

Vickery, P.J., Skerlj, P.F., Twisdale, L.A., 2000. Simulation of hurricane risk in the U.S. using empirical track model. Journal of Structural Engineering, October, 1222-1237. 